\title{
Building Blocks and Learning
}

CHARLES NELSON

Kean University

Using John Holland's model of complex adaptive systems, this paper explores how nonnative speakers of English learned to participate and to write in a first-year university rhetoric and composition course. Of particular interest is the emergence of students' internal models for writing and other class tasks through the reproduction and cross-over of conceptual building blocks, showing that much of learning and creativity is due to recombining what is known rather than invention de novo. The findings in this paper suggest that educators should design curricula around core conceptual building blocks that can be combined in various ways across novel situations and that can lead to an ongoing emergence of new building blocks. 
This is the timeless way of building: learning the discipline-and shedding it.

- Charles Alexander

\section{Introduction}

The discipline of second language (L2) composition is one concerned primarily with pedagogy. One of its major strands of research, contrastive rhetoric, "had its origins in pedagogical necessity."1 Concerned with first language (L1) interference in L2 writing in the classroom, Robert Kaplan's seminal article described differences in writing between English and other languages and asserted that paragraph development varied according to a culture's own rhetorical traditions, standards, and logic. ${ }^{2}$ An eventual implication was that by raising teachers', and in turn students', awareness of differences between L1 and L2 rhetorical conventions, teachers would be better informed to give appropriate feedback to students on their writing, and students would be enabled to appropriate the target language's conventions more easily.

Another major strand, inspired by the pioneering work of Flower and Hayes on L1 composing processes, ${ }^{3}$ has studied the processes of L2 writers, describing differences and similarities between skilled and novice L2 writ$\mathrm{ers}^{4}$ and between L1 and L2 writers. ${ }^{5}$ These studies promoted teaching language learners the strategies that experienced writers used, strategies that would help them generate ideas, make multiple drafts, revise globally then locally, and thus develop their writing skills.

In the last decade, Vygotsky's influence has led L2 composition researchers to investigate aspects of the social construction of texts and to assert that writing takes place in socially situated contexts ${ }^{6}$ and learning to write occurs through participating in communities of practice. ${ }^{7}$ This strand of research has endeavored to make visible the implicit, thus enabling language learners to participate in their academic and career communities. ${ }^{8}$

Generally speaking, these strands of research, along with others, have been descriptive in nature rather than explanatory. Cumming and Riazi write,

Considerable information now exists describing how people compose in a second language and the features of the texts they produce for single writing tasks, but we have very little information on how people actually learn to write in second languages or how teaching might influence this.... For this reason, research within educational programs is necessary not only to account realistically for what occurs in learning and teaching practices but also to help to explain them. ${ }^{9}$

The lack of explanatory research in second language composition is a curious phenomenon because, although various theories of learning already 
exist, such as constructivism and activity theory, they are used sparingly as explanatory models in the literature on L2 writing.

Another theory that may help the field of L2 composition to move toward an explanatory model of learning to write in another language (and of learning in general) is complexity theory. Complexity theory studies the dynamic processes, including those of learning, underlying all complex adaptive systems in an attempt to explain how they arise out of and maintain order amidst chaos.

In a complex adaptive system, independent agents dynamically interact with and adapt to one another and the environment. Agents adapt because, sensitive to feedback, they seek mutual accommodation and optimal benefit. These interactions and adaptations enable the agents within a system to self-organize (creating "order for free," as Kauffman called it ${ }^{10}$ ), thus leading to the emergence of new patterns and behaviors.

Although the concepts of complex systems may be rather new, their features are not. Many educators and researchers, although unfamiliar with complexity theory, use its terms, though not necessarily in the same technical sense. They talk about language learning as emergent, complex, nonlinear, and, at times, even chaotic. Language systems and language learning are considered to be dynamic ${ }^{11}$ and adaptive. ${ }^{12}$ Interaction among language learners is a key part of language development, ${ }^{13}$ and feedback plays a role in self-regulation and revision. ${ }^{14}$

The natural affinity between language learning and complexity theory has directly influenced several scholars in L2 research. In 1997, Larsen-Freeman introduced complexity theory to second language acquisition theorists, and her theory of "grammaring," a term highlighting grammar's dynamic nature, draws upon complexity theory. ${ }^{15}$ Van Lier's ecological approach to language education and classroom interaction is underpinned by complexity theory. ${ }^{16}$

Although complexity theory has made inroads into the periphery of L2 studies, it has remained almost non-existent in the area of L2 writing. If we wish to move forward in explaining how students learn to write in another language and to participate in an L2 environment, an appropriate place to begin would be with the two main processes common to all complex adaptive systems: adaptation and self-organization. However, they are so broad in nature as to make it difficult to distinguish complexity theory from other theories of change on those characteristics alone. One model that elaborates how those features operate is that of John Holland, a theoretical biologist and the father of genetic algorithms, and for that reason I have chosen it to investigate how students learn in a second language composition classroom. 


\section{Holland's Model of Complex Systems}

Holland proposes that all complex adaptive systems have four properties and three mechanisms. ${ }^{17}$ The four properties are aggregation, nonlinearity, flows, and diversity, and the three mechanisms are tagging, internal models, and building blocks. This paper will first cover all of the properties and mechanisms to provide a coherent picture of Holland's model. Then, it will focus on the role of building blocks in individual students' learning.

\section{Properties of complex adaptive systems}

Aggregation has two meanings. One is simplifying complexity by grouping items with similar characteristics, a primary method, Holland points out, by which we build models: Selecting certain details and ignoring others, we construct categories that become building blocks for our models. The second meaning refers to how complex systems behave. Through the combined interactions of less complex agents, complex collective behaviors emerge. Holland gives the example of an ant nest. An individual ant has a stereotypical behavior and usually dies when in situations not fitting its normal parameters. The ant nest, in contrast, is highly adaptive and can generally survive abnormal conditions.

More than two tiers of aggregations can exist, and the behavior at each level differs from other levels. Consider the following levels of aggregations, their interactions, and their emergent behaviors: cells, organs, individual human beings, and social and institutional groups. The tiers in an educational hierarchy, for instance, would be individual students and teachers, classes of students and teachers, schools, and school districts.

The differences in behavior at different levels is due to the property of nonlinearity. In nonlinearity, the behavior of the whole cannot be reduced to the sum of the parts. Obviously, the behavior of individual human beings cannot be understood simply by studying cells and organs, and similarly the behavior of complex educational systems cannot be understood by the behaviors of individual members, whether students, teachers, or administrators.

A third property of complex systems is flows. Flows refer to the movements of resources among agents via connectors that vary according to the system. For instance, in a food transportation system, the connectors are the transporting vehicles; the resources are the different foods; and the agents are the transmitting, storing, and receiving entities, such as farmers and grocery stores. The elements in a network change over time as agents adapt to various situations. "They are patterns that reflect changing adaptations as time elapses and experience accumulates."18 In a second language writing framework, flows include the movement of rhetorical knowledge among students and teachers within and across classroom boundaries. 
The final property is diversity. Educational institutions consist of many different types of teachers (science, English, history), staff members (janitors, secretaries), administrators, and students. Diversity results from complex systems because each agent's niche in the system "is defined by the interactions centering on that agent."19 This diversity is a dynamic pattern because agents engage in progressive adaptations via their interactions with other agents, thus constantly changing their niches in the system.

\section{Mechanisms}

The mechanism of tagging facilitates selective interactions and thus the formation of aggregates. Tags are identifiers and categorizers. They can be badges identifying people who work in a company, thus setting the boundaries of the aggregate. They can also be values that identify potential friends or mates for future interactions and screen out others. Tags, therefore, also influence flows because they

almost always define the network by delimiting the critical interactions, the major connections. Tags acquire this role because the adaptive processes that modify [complex adaptive systems] select for tags that mediate useful interactions and against tags that cause malfunctions. ${ }^{20}$

A second mechanism is schemas, or what Holland calls internal models. Internal models are mechanisms for anticipating situations. Unlike in schema theory, however, where schemas are considered to be only explicit knowledge, ${ }^{21}$ Holland's internal models can be both tacit and overt, with tacit models implicitly directing current actions and overt models employing explicit, internal consideration of alternative lines of action, a process Holland called lookahead.

Internal models develop from interactions with the environment through three steps: reproduction through fitness, recombination via cross-over, and replacement. If a schema is fit, that is, successful in anticipating situations and guiding behavior, it acts as a parent in reproducing new schemas. In recombination, parts of different parent schemas (i.e., building blocks, see below) cross over to each other and recombine to create, new offspring schemas. These offspring schemas can replace other schemas already in the population. If we translate these terms into composition classroom analogies, reproduction means that students continue to use schemas that work in their essays. Recombination refers to students incorporating, for example, new concepts of writing into their present concepts so that both old and new concepts are used in some hybrid form. Replacement refers to students replacing an older schema for writing with a new, usually hybrid, schema.

The final mechanism is building blocks. Holland gave the example of a human face, in which the common building blocks would include hair, fore- 
head, eyebrows, eyes, and so on, up to ten blocks. He also broke each facial building block into ten alternatives (e.g., blue eyes, brown eyes, hazel eyes, etc.), which gave a total of 100 building blocks. If one were to choose one alternative building block from each of ten bags of facial components, there would be 10 billion $\left(10^{10}\right)$ distinct faces with only 100 building blocks.

Another example would be the four bases of DNA. Various permutations of these four building blocks have given rise to myriads of species, all uniquely adapting to and fitting their environmental niches.

When applied to composition, Holland's model of building blocks differs from those in which teachers "transmit" a static blueprint of writing to students who, in turn, learn to assemble various components in a linear, lock-step manner toward a predetermined product. Rather, in Holland's model, the focus is on interactions, adaptation, and emergence. Like DNA, interactions between rhetorical building blocks and social environments generate species of arguments, each one adapting to social niches, such as political speeches, academic articles, newspaper editorials, and family squabbles. Thus, the interactions of a few building blocks can generate novelty and, as will be seen, learning.

\section{Method and Context}

This case study looked at my own first-year university rhetoric and composition course for international students..$^{22}$ There were 13 students in the class coming from eight different countries. ${ }^{23}$ The students had resided in the U.S. for one to three years. Seven were science majors, four were in liberal arts, one in business, and one in fine arts. Classifications ranged from freshman to graduate student, ages from 19 to 31, and writing experiences from very little to one who had written two novels in her native language.

Over the course of a semester, students wrote three argumentative papers (including multiple drafts and peer and teacher reviews) of three to five double-spaced pages, wrote observations of class-related activities, and evaluated their learning over the semester.

The observations and self-evaluation are part of a portfolio system of assessment called the Learning Record Online (LRO). ${ }^{24}$ Observations in the LRO are brief notes on class-related activity in which the students engage either in class or out of class. In this class, four observations a week were expected with at least two observations a week made outside of class. Particular emphasis was placed upon observations out of class to help students form connections between classroom learning and their own societal practices, so that learning could become more meaningful. In addition, observations served as documentation for student learning over the semester. That is, students had to evaluate their work and claim a grade, supporting 
their claims with evidence from their work and observations. In providing evidence, students were guided by the need to show development in the three course strands of rhetoric, research, and collaboration, and by the LRO's framework of five dimensions of learning: confidence and independence, knowledge and understanding, skills and strategies, use of prior and emerging experience, and reflectiveness.

Data collection for this article came primarily from student observations and three formal, semi-structured tape-recorded interviews with the students (one each at the beginning, middle, and end of the semester for 40 to 70 minutes). I conducted the interviews in a small, private room in the main library. ${ }^{25}$ Each interview had 27 to 42 mostly open-ended questions that covered students' education and writing backgrounds; perspectives and understanding of class assignments, concepts, and class practices; and their own approaches to writing, including how their perspectives and writing practices changed over the semester and how they handled difficulties in class assignments. ${ }^{26}$

Analysis of the interviews and observations occurred almost entirely after the semester had ended as time was insufficient to both collect data and also analyze it while carrying out my responsibilities as a teacher. Thus, my role as teacher predominated during the semester. After the class had ended, my role became fully that of researcher with the advantage of retaining the insights into the class activity and my students I had as their instructor. ${ }^{27}$

Because this was a theory-informed case study, my approach to selecting data for analysis was to look for patterns of interactions, relationships, and adaptations among the students with each other and the teacher, with course assignments, and with cultural artifacts, such as the LRO. In determining patterns, I simultaneously took two approaches: One, I treated each student individually, focusing on their own words in order to develop a "thick description" of the participants' perspectives. ${ }^{28}$ Two, I applied Holland's model to their perspectives and patterns to ascertain its usefulness in explaining them.

\section{Discussion}

In exploring how individuals learn and generate creativity in novel situations, this paper will look at how building blocks are reproduced, recombined through cross-over, and replaced.

\section{Reproduction}

Building blocks that have worked in the past are reproduced in new situations. Yiping, a student from China, had almost no experience in writing, 
but as an accomplished pianist, she embodied the building blocks of music and naturally selected them in learning to write in English. ${ }^{29}$ To understand how other authors wrote, she read their essays in the way that she listened to music:

When reading, we will be able to get all kinds of information either we are trying to find in particular articles or the writers meant to give to their audience. But at the time when we are learning to write, in the course of reading the thing we will be aware of is not only to find out information but also how other authors are making their essay. It is like listening to music recordings. When performers are listening to the music, the thing that they are paying attention to is not only to appreciate how beautiful that music is but to realize how that beautiful music has been made as well.

For arranging the concepts in her papers, she reproduced her "master plan" conceptual building block for playing the piano. Other students also reproduced building blocks for organizing their essays. Fengshan transferred the model of a flow chart from computer science, and Ahmet and Sabah used outline methods: Ahmet to organize his ideas, and Sabah to distinguish "which information fit which criteria."

Sometimes a building block or schema may be reproduced that is not appropriate for a new situation. International students have rhetorical conventions (and a world knowledge) in their native language that differ from practices in another language. For instance, compared to U.S. conventions, some cultures are more reader-responsible. They prefer, as Lihua wrote with respect to humor, to "let the readers find [the meaning] by themselves." Accordingly, when reading Yiping's second paper, I did not understand the connection between her paragraph on cybercrime and the paper's theme of online relationships not being real. Only with her explaining the connection in person and in considerably more detail did I come to understand it. While analyzing her work on a later paper, Yiping came to a similar conclusion:

When reorganizing the ideas, I found out that most of the ideas that seem inappropriate or cannot be understood by people are usually because of the language. ... We think originally in the way we express in our own language, and they are not quite fit the way English is expressed ... [which] is causing much miscommunication.

By becoming aware that her building blocks were ill-fitting, Yiping had taken a step in adapting to new circumstances and rhetorical conventions.

\section{Cross-over and recombination}

The examples above seem to be mostly cases of reproduction into new situations, although some adaptation likely occurred to help the building blocks fit into the new contexts. However, when building blocks are perceived as 
not fitting one's purpose well, a dissonance occurs that can propel one to "combine relevant, tested building blocks to model the situation in a way that suggests appropriate actions and consequences, ${ }^{\prime \prime 30}$ thus generating novelty.

At the semester's end, students had to turn in a final self-evaluation of their learning. Most students described their learning in a matter-of-fact manner similar to the Midterm Self-Evaluation below. Ahmet, however, was not satisfied with mere description. He wrote, "I did not want just to list the things I learned. Instead I wanted to write an essay," and elsewhere he mentioned that he wanted his writing to be "vivid." Contrast his introductory sentences from the Midterm and Final Self-Evaluations:

\begin{abstract}
Midterm Self-Evaluation
As I noted in my reflection essay

I started this class believing that writers are born. Thus I didn't start this class expecting to be a good writer.
\end{abstract}

\begin{abstract}
Final Self-Evaluation
"RHE306Q in UT? Are you mad? You are going to write a lot" said my friend after I registered for this class. "No choice for a sponsored and a poor student" I said.
\end{abstract}

His anecdote in the Final Self-Evaluation imitated an example I had given in class on making introductions more interesting. By integrating a conversational scene into his previous "list" model of self-evaluation, Ahmet transformed the class genre for self-evaluation.

Another transformation was seen in students' optional presentations. ${ }^{31}$ The first three were the familiar stand-up-and-talk presentation seen in many classes. The fourth presentation, given by Maria, was different: She gave a PowerPoint presentation. A computer science major looking ahead to a career as a consultant in a company, Maria had written at the beginning of the semester that one of her goals was to be able to "write a good presentation to show to [her] Boss at work someday." She had likely seen PowerPoint elsewhere and understood that it was used in business presentations. By combining PowerPoint technology with standing-up-and-talking behavior, she generated a new model for presentations, at least for our class, and an impressive one. Other students soon followed suit: Tatiana and Lihua reproduced the new model in their presentations. Eventually, the new "offspring" became a "parent" in its own right when at the end of the semester, Julie, an advertising major, combined into her PowerPoint presentation a building block from her major: a video of an advertisement on hair color and conditioner illustrating the application of rhetoric to her major. Through the aggregations of simple actions, presentations grew more sophisticated and their rhetoric more persuasive. 
Dissonance leading to cross-over and recombination was also seen in Maria's writing of an evaluation paper. Maria wanted to contend that interracial marriages are a good relationship. However, she was quite "frustrated" in devising criteria for her claim because, of course, not all interracial marriages have good results. Progressing through a series of interactions with writing center tutors, myself, and friends, she revised her claim to "Interracial marriages are not bad marriages" and, in the process, departed from the Develop-Criteria-then-Match format taught in class to an arrangement of Develop-Criteria-Rebuttal-then-Match. Thus, we see the building block of rebuttals crossing over with the blocks of developing criteria and matching claims, resulting in a new format "offspring" for Maria.

\section{Replacement}

It is normal for both "parent" and "offspring" building blocks to coexist. In time, however, the "fitter" building blocks increase in the population of internal models, eventually replacing those less fit. Again, internal models anticipate situations, thus governing behavior. Many of those students, whose previous educational experiences were of a lecture-format nature, did not appreciate collaborative work in class. In time, most students came to see collaboration as useful. Julie noted that her classmates "taught [her] how to see it from [a] different point of view," and Ahmet felt that collaboration was "most helpful ... You have an idea ... but sometimes you may get stuck or people have different ideas ... So you know, you can solve almost every problem with collaboration."

No doubt, students' awareness of collaboration was stimulated, at least to some degree, by my requirement that they show learning in this area. ${ }^{32}$ Although this requirement could have influenced students to write observations to fit my expectations, this outcome does not seem to be the case, as students did note disadvantages of group work in their observations. In fact, Linda wrote, "For me working in groups is not as efficient as working alone." Nevertheless, their observations, including Linda's, showed an awareness of its usefulness in their writing, and at least one student continued to value collaboration after the class had ended. Maria was initially not fond of collaboration. However, through successful collaborative experiences, she seemed to have developed a building block of collaboration that replaced her "work alone" behavior for writing, as indicated by her email one year later:

I think one of the things that I learned most from your class is collaboration. I used to think that my own writing is good enough and I would not nee[d] other people's opinions. But in your class, you wanted us to collaborate with our peers, and also to go to the Writing Center. You also set 
some time to meet with you to discuss our papers. It turned out that the collaboration part really changed the way I write. People could see mistakes that I don't see, and they could suggest ways to go about it. I'm taking another writing class now at UT (Business Communication). And now, everytime I write a memo or a letter, I always go to my Prof's Office Hours for collaboration, and then to the Writing Center to make sure everything is allright.

Generally speaking, success with a building block favors its replacing a less successful block. Sabah, a geophysics major, employed a reading model that "consider[ed] everything in the textbook as important facts that I need to memorize." Because the method was "tiring" and "bor[ing]," she adapted by using Toulmin logic and the concept of ethos to study the text:

I was glad that I could pick up the crux of the paragraph and I just had to read the evidence to make the claim clearer for me without forcing myself memorizing it since I already knew the concept. Furthermore, in the textbook there were a lot of citations and quotations and it made it more interesting for me now because by knowing the importance of credibility, I kinda believe the author and it was exciting following his arguments.

Sabah replaced her memorizing schema with building blocks of rhetoric that were more fit for understanding and remembering the information in her geology textbooks. In the process of replacement, a new internal model emerged via the cross-over of rhetoric with the discipline of geophysics, so that knowledge of geophysics was no longer merely a matter of accumulating facts but of positioning and supporting arguments.

\section{Conclusion}

Building blocks are a metaphor for modeling how simplicity generates complexity. They indicate that much of learning and creativity is not invention de novo. Rather, via the crossing-over and recombining of pre-existing building blocks, learning and creativity emerge from the continual evolving of diverse species of new building blocks.

From a classroom ecology perspective, building blocks flowed across individuals through observation and imitation. Thus, one pedagogical implication is the need to promote interactions and the flow of knowledge among students and others. ${ }^{33}$ This class, like many composition classes, did this through peer reviews of essays, small group work, electronic message boards, and so on. However, except for their journal observations, students were on their own in linking composition to other subjects, disciplines, and personal interests outside the class, although they obviously did so. More thought needs to be given to how we can structure support for intertwining rhetoric into other disciplines and student interests-not simply 
through an adaptation of a Writing Across the Curriculum Program, but in such a way that a diversity of interactions and knowledge flows aid students in adapting to novel contexts and in generating new building blocks.

From a student as agent perspective, the reproduction and recombination of building blocks were enhanced, I believe, through the use of the Learning Record Online. This portfolio system required that students reflect on their learning, connecting it to their previous and present practices within the class and without. In particular, observation journals raised students' awareness of their practices within and across class boundaries. Such an awareness is important in helping international students make explicit the implicitly understood building blocks of L1 and L2 rhetorical conventions so that they can reproduce and recombine them appropriately. In addition, by focusing students' attention on how classroom concepts are at play in their own interests and societal practices, observations helped learning become meaningful.

Another pedagogical implication is the need to focus curricula around building blocks that are particularly fruitful for recombining. Of course, as seen above, students naturally select and combine building blocks on their own without direction from the teacher. And, of course, most teachers, myself included, provide a variety of strategies and concepts for students to employ in writing. However, a haphazard, cornucopia approach to pedagogy misses the point. Holland writes:

We gain a significant advantage when we can reduce the building blocks at one level to interactions and combinations of building blocks at a lower level: the laws at the higher level derive from the laws of the lower-level building blocks. This does not mean that the higher-level laws are easy to discover, any more than it is easy to discover theorems in geometry because one knows the axiom. It does add a tremendous interlocking strength to the scientific structure. ${ }^{34}$

In other words, if there are kernel building blocks from which all other building blocks in composition can be derived, then learners, through a process of recombining them across novel and varied contexts, can gain a deeper, conceptual understanding of the discipline than they would otherwise. In this class, the primary concepts were audience, elements of Toulmin logic, and pathos, ethos, and logos. As this study looked more broadly at learning rather than composition alone, it is not clear if these concepts are the most fruitful for recombining nor whether any of these are "kernel" building blocks for learning to write in a second (or first) language. More research needs to be directed toward identifying kernel building blocks and determining if and how they can promote a deeper conceptual understanding of writing. 
The metaphor of building blocks indicates that there is no optimum state of learning, a condition that would imply equilibrium. Instead, there is a process of dissonance, or disequilibrium, that propels students to adapt and recombine building blocks to meet the needs of interacting with their environment. Consequently, learning consists of an ongoing emergence of new building blocks, not only at the level of concepts but also at the level of rules governing concepts, so that eventually students may shed the discipline they have studied and create it anew.

\section{Acknowledgements}

I would like to thank Brent Davis, Renata Phelps, and the anonymous reviewers for their insightful and helpful comments on an earlier version of this paper.

\section{Endnotes}

1. Robert B. Kaplan, "Contrastive Rhetoric and Second Language Learning: Notes toward a Theory of Contrastive Rhetoric," in Writing across Languages and Cultures: Issues in Contrastive Rhetoric, ed. Alan C. Purves (Newbury Park, California: Sage, 1988).

2. Robert B. Kaplan, "Cultural Thought Patterns in Inter-Cultural Education," Language Learning 16 (1966).

3. Linda Flower and John R. Hayes, "A Cognitive Process Theory of Writing," College Composition and Communication 32 (1981), Linda Flower and John R. Hayes, "The Dynamics of Composing: Making Plans and Juggling Constraints," in Cognitive Processes in Writing, ed. L. Gregg and E. Steinberg (Hove, Sussex and Hillsdale, NJ: Lawrence Erlbaum Associates, 1980), Linda Flower and John R. Hayes, "Images, Plans, and Prose: The Representation of Meaning in Writing," Written Communication 1 (1984).

4. Miyuki Sasaki, "Toward an Empirical Model of EFL Writing Processes: An Exploratory Study," Journal of Second Language Writing 9 (2000), V. Zamel, "The Composing Processes of Advanced ESL Students: Six Case Studies," TESOL Quarterly 17 (1983).

5. Ilona Leki and Joan G. Carson, "'Completely Different Worlds": EAP and the Writing Experiences of ESL Students in University Courses," TESOL Quarterly 31 (1997), Christine Parkhurst, "The Composition Process of Science Writers," English for Specific Purposes 9 (1990), Tony Silva, "Toward an Understanding of the Distinct Nature of L2 Writing: The ESL Research and Its Implications," TESOL Quarterly 27 (1993).

6. Luis C. Moll, “Teaching Second Language Students: A Vygotskian Perspective," in Richness in Writing: Empowering ESL Students, ed. Donna M. Johnson and Duane H. Roen (New York: Longman, 1989).

7. Diane Belcher, "The Apprenticeship Approach to Advanced Academic Literacy: Graduate Students and Their Mentors," English for Specific Purposes 13 (1994).

8. Ken Hyland, "Genre-Based Pedagogies: A Social Response to Process," Journal of Second Language Writing 12 (2003). 
9. Alister Cumming and Abdolmehdi Riazi, "Building Models of Adult Second-Language Writing Instruction," Learning and Instruction 10 (2000).

10. Stuart Kauffman, At Home in the Universe: The Search for the Laws of Self-Organization and Complexity (New York: Oxford University Press, 1995).

11. Philip Herdina and Ulrike Jessner, A Dynamic Model of Multilingualism: Perspectives of Change in Psycholinguistics, ed. John Edwards, Multilingual Matters Series (Clevedon, UK: Multilingual Matters Ltd, 2002), Paul Kei Matsuda, “Contrastive Rhetoric in Context: A Dynamic Model of Writing," Journal of Second Language Writing 6 (1997), Benhu Wu, "Towards an Understanding of the Dynamic Process of L2 Classroom Interaction," System 26 (1998).

12. T. Dary Erwin and Priscilla K. Coleman, "The Influence of Intercultural Experiences and Second Language Proficiency on College Students' Cross-Cultural Adaptability," International Education 28 (1998), John H. Schumann, "Research on the Acculturation Model for Second Language Acquisition," Journal of Multilingual and Multicultural Development 5 (1986).

13. Diane D. Belcher, "Authentic Interaction in a Virtual Classroom: Leveling the Playing Field in a Graduate Seminar," Computers and Composition 16 (1999), Susan M. Gass, Input, Interaction, and the Second Language Learner (Mahwah, NJ: Lawrence Erlbaum, 1997), James P. Lantolf and Aneta Pavlenko, "Sociocultural Theory and Second Language Acquisition," Annual Review of Applied Linguistics 15 (1995).

14. Ali Aljaafreh and James P. Lantolf, "Negative Feedback as Regulation and Second Language Learning in the Zone of Proximal Development," The Modern Language Journal 78 (1994), Fiona Hyland, "The Impact of Teacher Written Feedback on Individual Writers," Journal of Second Language Writing 6 (1998).

15. Diane Larsen-Freeman, "Chaos / Complexity Science and Second Language Acquisition," Applied Linguistics 18 (1997), Diane Larsen-Freeman, Teaching Language: From Grammar to Grammaring (Canada: Heinle, 2003).

16. Leo van Lier, "Approaches to Observation in Classroom Research: Observation from an Ecological Perspective," TESOL Quarterly 31 (1997), Leo van Lier, "From Input to Affordance: Social-Interactive Learning from an Ecological Perspective," in Sociocultural Theory and Second Language Learning, ed. James P. Lantolf (Oxford: Oxford University Press, 2000).

17. John H. Holland, Hidden Order: How Adaptation Builds Complexity (Reading, Massachusetts: Helix Books, 1995).

18. Ibid., 23.

19. Ibid., 27.

20. Ibid., 23.

21. Patricia A. Alexander, Diane Lemonnier Schallert, and Victoria C. Hare, "Coming to Terms: How Researchers in Learning and Literacy Talk About Knowledge," Review of Educational Research 61 (1991).

22. This study was a smaller part of my dissertation: Charles P. Nelson, "Contradictions in Learning to Write in a Second Language Classroom: Insights from Radical Constructivism, Activity Theory, and Complexity Theory" (Dissertation, The University of Texas at Austin, 2002).

23. Initially, there were 14 students, but one stopped attending after two months.

24. For a complete description of the LRO, its history, and pedagogical underpinnings, see Margaret A. Syverson and Center for Language in Learning, The Learning Record Online (Computer Research and Writing Laboratory, 1995 [cited July 1, 2004]); available from http:/ / www.cwrl.utexas.edu/ syverson/olr/. 
25. Two of the initial interviews were conducted by another participant-observer, who stopped participating due to time conflicts.

26. Copies of the interview questions can be seen in the appendices of my dissertation, Charles P. Nelson, op. cit.

27. For the privileged understanding of the classroom teacher with respect to classroom data, see Richard Pring, Philosophy of Educational Research (London: Continuum, 2000).

28. Clifford Geertz, The Interpretation of Cultures (New York: Basic, 1973), Clifford Geertz, Local Knowledge (New York: Basic, 1983).

29. All names are pseudonyms.

30. Holland, op. cit., p. 37.

31. To obtain an A in the class, students had to go significantly beyond what was required. In addition to other activities, some students chose to give presentations in working toward an A.

32. As mentioned earlier, students had to evaluate their development over the semester in the three areas of rhetoric, research, and collaboration.

33. For a fuller discussion of this topic, see Charles P. Nelson, "Ch. 9: Learning Networks and Knowledge Flows in the L2 Composition Classroom," in Second Language Writing, ed. Kuldip Kaur (Kuala Lumpur: Sasbadi, 2004).

34. John H. Holland, op. cit., p. 36. Holland gives the example of quarks as the fundamental building block in physics, which when combined, give rise to the next level of nucleons, which in turn combine to form atoms, and so on.

\section{References}

Alexander, Patricia A., Diane Lemonnier Schallert, and Victoria C. Hare. "Coming to Terms: How Researchers in Learning and Literacy Talk About Knowledge." Review of Educational Research 61 (1991): 315-343.

Aljaafreh, Ali, and James P. Lantolf. "Negative Feedback as Regulation and Second Language Learning in the Zone of Proximal Development." The Modern Language Journal 78 (1994): 465-483.

Belcher, Diane D. "The Apprenticeship Approach to Advanced Academic Literacy: Graduate Students and Their Mentors." English for Specific Purposes 13 (1994): 23 24.

_. "Authentic Interaction in a Virtual Classroom: Leveling the Playing Field in a Graduate Seminar." Computers and Composition 16 (1999): 253-267.

Cumming, Alister, and Abdolmehdi Riazi. "Building Models of Adult Second-Language Writing Instruction." Learning and Instruction 10 (2000): 55-71.

Erwin, T. Dary, and Priscilla K. Coleman. "The Influence of Intercultural Experiences and Second Language Proficiency on College Students' Cross-Cultural Adaptability." International Education 28 (1998): 5-25.

Flower, Linda, and John R. Hayes. "A Cognitive Process Theory of Writing." College Composition and Communication 32 (1981): 365-387.

. "The Dynamics of Composing: Making Plans and Juggling Constraints." In Cognitive Processes in Writing, edited by L. Gregg and E. Steinberg, 31-50. Hove, Sussex and Hillsdale, NJ: Lawrence Erlbaum Associates, 1980.

. "Images, Plans, and Prose: The Representation of Meaning in Writing." Written Communication 1 (1984): 120-160. 
Gass, Susan M. Input, Interaction, and the Second Language Learner. Mahwah, NJ: Lawrence Erlbaum, 1997.

Geertz, Clifford. The Interpretation of Cultures. New York: Basic Books, 1973.

- Local Knowledge. New York: Basic Books, 1983.

Herdina, Philip, and Ulrike Jessner. A Dynamic Model of Multilingualism: Perspectives of Change in Psycholinguistics. Edited by John Edwards, Multilingual Matters Series. Clevedon, UK: Multilingual Matters Ltd, 2002.

Holland, John H. Hidden Order: How Adaptation Builds Complexity. Reading, Massachusetts: Helix Books, 1995.

Hyland, Fiona. “The Impact of Teacher Written Feedback on Individual Writers." Journal of Second Language Writing 6 (1998): 255-286.

Hyland, Ken. "Genre-Based Pedagogies: A Social Response to Process." Journal of Second Language Writing 12 (2003): 17-29.

Kaplan, Robert B. "Contrastive Rhetoric and Second Language Learning: Notes toward a Theory of Contrastive Rhetoric." In Writing across Languages and Cultures: Issues in Contrastive Rhetoric, edited by Alan C. Purves, 275-304. Newbury Park, California: Sage, 1988.

—. "Cultural Thought Patterns in Inter-Cultural Education." Language Learning 16 (1966): 1-20.

Kauffman, Stuart. At Home in the Universe: The Search for the Laws of Self-Organization and Complexity. New York: Oxford University Press, 1995.

Lantolf, James P., and Aneta Pavlenko. "Sociocultural Theory and Second Language Acquisition." Annual Review of Applied Linguistics 15 (1995): 108-124.

Larsen-Freeman, Diane. "Chaos/Complexity Science and Second Language Acquisition." Applied Linguistics 18 (1997): 141-165.

- Teaching Language: From Grammar to Grammaring. Canada: Heinle, 2003.

Leki, Ilona, and Joan G. Carson. "“Completely Different Worlds": EAP and the Writing Experiences of ESL Students in University Courses." TESOL Quarterly 31 (1997): 39-69.

Matsuda, Paul Kei. "Contrastive Rhetoric in Context: A Dynamic Model of Writing." Journal of Second Language Writing 6 (1997): 45-60.

Moll, Luis C. "Teaching Second Language Students: A Vygotskian Perspective." In Richness in Writing: Empowering ESL Students, edited by Donna M. Johnson and Duane H. Roen, 55-69. New York: Longman, 1989.

Nelson, Charles P. “Ch. 9: Learning Networks and Knowledge Flows in the L2 Composition Classroom." In Second Language Writing, edited by Kuldip Kaur, 230-253. Kuala Lumpur: Sasbadi, 2004.

—. "Contradictions in Learning to Write in a Second Language Classroom: Insights from Radical Constructivism, Activity Theory, and Complexity Theory." PhD diss., The University of Texas at Austin, 2002.

Parkhurst, Christine. "The Composition Process of Science Writers." English for Specific Purposes 9 (1990): 169-179.

Pring, Richard. Philosophy of Educational Research. London: Continuum, 2000.

Sasaki, Miyuki. "Building an Empirically-Based Model of EFL Learners' Writing Processes." In New Directions for Research in L2 Writing, edited by Sarah Ransdell and Marie-Laure Barbier, 49-80. Dordrecht: Kluwer Academic Publishers, 2002.

- "Toward an Empirical Model of EFL Writing Processes: An Exploratory Study." Journal of Second Language Writing 9 (2000): 259-291. 
Schumann, John H. "Research on the Acculturation Model for Second Language Acquisition." Journal of Multilingual and Multicultural Development 5 (1986): 379-393.

Silva, Tony. "Toward an Understanding of the Distinct Nature of L2 Writing: The ESL Research and Its Implications." TESOL Quarterly 27 (1993): 657-677.

Syverson, Margaret A., and Center for Language in Learning. The Learning Record Online. Computer Research and Writing Laboratory, 1995. Available from http:// www.cwrl.utexas.edu/ syverson/olr/ (accessed July 1, 2004).

van Lier, Leo. "Approaches to Observation in Classroom Research: Observation from an Ecological Perspective." TESOL Quarterly 31 (1997): 783-787.

. "From Input to Affordance: Social-Interactive Learning from an Ecological Perspective." In Sociocultural Theory and Second Language Learning, edited by James P. Lantolf, 245-259. Oxford: Oxford University Press, 2000.

$\mathrm{Wu}$, Benhu. "Towards an Understanding of the Dynamic Process of L2 Classroom Interaction." System 26 (1998): 525-540.

Zamel, V. "The Composing Processes of Advanced ESL Students: Six Case Studies." TESOL Quarterly 17 (1983): 165-187.

\begin{abstract}
About the Author
Charles P. Nelson is Assistant Professor of ESL Writing at Kean University, New Jersey, USA. He received his doctorate from The University of Texas at Austin, and his research interests include second language writing, portfolio assessment, complexity theory, and sociocultural and constructivist theories of learning.
\end{abstract}

